\title{
RESISTÊNCIA E EMPODERAMENTO: OS CONCURSOS DE BELEZA NEGRA DO IFMS/IFSP
}

\author{
RESISTANCE AND EMPOWERMENT:THE CONTESTS OF \\ BLACK BEAUTY IN IFMS/IFSP
}

\author{
Guilherme Costa Garcia Tommaselli ${ }^{1}$ \\ Augusto Mular Miceno ${ }^{2}$ \\ Tatiane Helena Borges de Salles ${ }^{3}$
}

\section{RESUMO}

Os Institutos Federais são equiparados às Universidades Federais. Devem conciliar, portanto, a tríade Ensino, Pesquisa e Extensão. Criados há 10 anos, por meio da Lei 11.892/2008, os Institutos Federais de Educação, Ciência e Tecnologia oferecem cursos técnicos e superiores orientados pelo indicador 50/30/20: ao menos 50\% de cursos técnicos, até $30 \%$ de cursos superiores de bacharelado tradicional e tecnológico e pelo menos $20 \%$ de licenciaturas. Trata-se de instituições públicas em processo de construção identitária, sobretudo naquelas que surgiram por força da lei, sem a infraestrutura física e corpo de servidores advindos dos escombros dos antigos Cefets. Diz-se isso porque o relato de organização de concursos de Beleza Negra no campus Três Lagoas do IFMS revela potente experiência junto ao público adolescente de estudantes de Ensino Médio autodeclarados negros. Compartilha-se ação de extensão que, na prática, faz sucumbir roteiros, padrões, metodologias e expectativas.

Palavras-chaves: educação; beleza negra; empoderamento.

\section{ABSTRACT}

Federal institutes are equalled to federal universities. They must therefore reconcile the triad of teaching, research and extension. Created 10 years ago, through the law 11.892/2008, the federal Institutes of Education, science and technology offer technical and superior courses guided by the 50/30/20 indicator: At least 50\% of technical courses, up to 30\% of traditional and technological bachelor's degrees and at least $20 \%$ of undergraduate. These are public institutions in the process of

\footnotetext{
${ }^{1}$ Doutor em Educação pela Universidade Estadual Paulista Júlio de Mesquita Filho. Atualmente é docente de sociologia do Instituto Federal de Educação, Ciência e Tecnologia de Mato Grosso do Sul. E-mail: guilherme.tommaselli@ifms.edu.br

${ }^{2}$ Graduado em Comunicação Social - Publicidade e Propaganda pela Universidade Estadual do Centro-Oeste, UNICENTRO. E-mail: augusto.miceno@ifsp.edu.br

${ }^{3}$ Graduada em Ciência da informação com a habilitação em Biblioteconomia pela Pontifícia Universidade Católica de Campinas (2006) e Biblioteconomia (2011) pela Pontífica Universidade Católica de Campinas. E-mail: tatiane.salles@ifsp.edu.br
} 
identity construction, especially those that are under the law, without the physical infrastructure and body of servers coming from the rubble of the ancient Cefets. This is said because the report on the organization of Black beauty contests on the campus of IFMS reveals a powerful experience with the adolescent public Self-declared blacks. It shares an extension action that, in practice, does succumb to scripts, patterns, methodologies and expectations.

Keywords: education; black beauty; empowerment.

\section{INTRODUÇÃO}

Há oito anos, o campus Três Lagoas do IFMS (Instituto Federal de Mato Grosso do Sul) tem atuado no eixo das relações étnico-raciais. O trabalho desenvolvido desde 2011 , com a primeira Semana da Consciência Negra, como veremos, expandiu-se e se desenvolveu, ganhando dimensões não imaginadas. O relato de experiência objeto deste artigo é fruto de uma ação conjunta entre o campus Três Lagoas do IFMS e o campus Votuporanga do IFSP, que em um processo de troca de experiências através do NEABI (Núcleo de Estudos Afro-Brasileiros e Indígenas) realizaram uma ação em parceria, na construção do primeiro concurso de beleza negra do campus Votuporanga.

A primeira Semana da Consciência Negra do campus Três Lagoas do Instituto Federal de Mato Grosso do Sul (IFMS), liderada pelos professores das disciplinas de História e Sociologia, ocorreu em 2011, ano em que as atividades da unidade educacional iniciaram em sede provisória naquele município.

Deste modo, o campus Três Lagoas tornou-se pioneiro em realizar ações e reflexões sobre as relações étnico-raciais, assim como, a ser o primeiro campus a incluir, já em 2012, a semana da consciência negra no calendário escolar. O processo de inserção da consciência negra no calendário escolar, no entanto, foi um processo conflituoso, apesar de respaldado na lei $10.639 / 03$.

O Brasil padece de um racismo estrutural e institucional, o que faz com que a inserção de elementos que fujam à matriz do branqueamento eurocêntrica cause estranhamentos. Não foi diferente no campus Três Lagoas do IFMS, em que, durante os anos de implantação da unidade, sempre houve corrente reativa à realização das atividades do evento "Semana da Consciência Negra", assim como uma diminuição de sua importância quando comparada a 
outros eventos institucionais como a "Semana do Meio Ambiente" ou a "Semana Nacional de Ciência e Tecnologia" (SNC\&T), esta última obrigatória na Rede Federal de Educação Profissional, Científica e Tecnológica (EPC\&T).

É nesse contexto de enfrentamento que se dá a tarefa de tornar efetiva a lei 10.639/03 no campus em questão, desenvolvendo nas áreas de História e Sociologia, de forma planejada e interdisciplinar, uma nova versão do currículo, que se volta para o povo negro como ponto central de debate, nos dois campos. Conteúdos preparados e planejados visando, sempre que possível e pertinente, a inserir a figura de negros e negras e da África, de forma central e com uma perspectiva crítica.

O processo de implementação da lei 10.639/03 de forma efetiva no campus Três Lagoas, deu-se, antes de tudo, pela vontade e interesses dos educadores envolvidos no processo. A lei 10.639/03, que institui a obrigatoriedade do ensino da história e da cultura Africana e AfroBrasileira, não garante que ela seja posta em prática nas escolas do país como um projeto educacional necessário e urgente.

$\mathrm{Na}$ verdade, o que se observa em um tom geral é que a efetivação da lei, depende da vontade dos gestores e da equipe docente. Ou seja, a lei existe, mas para que se torne efetiva ela necessita de ações particulares, individuais, pois não há uma política de estado voltada para a promoção de uma educação antirracista. Neste caso, a produção da educação antirracista tem dependido de ações localizadas, em que há um encontro de sujeitos e coletivos que reconhecem a necessidade de promover uma educação antirracista com urgência, como o caso de Três Lagoas, em que se desenvolveu uma tradição de produzir um enfrentamento pedagógico ao racismo estrutural.

A experiência do campus Três Lagoas em enfretamento ao racismo se expande a medida em que o trabalho começa a ganhar dimensões não planejadas. Neste contexto, em 2016, o trabalho que até então se restringia ao campus, inicia sua primeira inserção na educação infantil, através do desenvolvimento do projeto de extensão Malungos de Zumbi e Dandara. A prática extensionista proporcionou aos coordenadores e membros do projeto, uma potencialização das experiências em combater o racismo. 
É durante a experimentação do projeto de extensão e as discussões realizadas pelo grupo de trabalho do projeto que surge a proposta de organização do primeiro concurso de beleza negra do IFMS, que mais tarde viria a inspirar iniciativas como a do campus Votuporanga do IFSP e outros campus do IFMS, demonstrando o potencial e alcance do trabalho realizado.

A extensão, neste caso, torna-se uma possibilidade de potencializar a experiência pedagógica de educação antirracista desenvolvida no campus Três Lagoas que, além de cumprir com o previsto na Lei de Diretrizes e Bases (LDB), alterada pelas leis 10.639/2003 e $11.645 / 2008$, de fato oferece atividades e oportunidades informativas e formativas de empoderamento de jovens estudantes afrodescendentes, público-alvo das experiências de Extensão em questão.

Nesse caso, a ação de Extensão se coaduna com a necessidade emergente em promover autoestima junto ao público-alvo, bem como contribuir para a autoconfiança, ao valorizar a cultura, a beleza e a estética negra, superando padrões eurocêntricos.

Nesse sentido, é atual a lição de Paulo Freire contida em "Extensão ou Comunicação", à medida que se aplica para a perspectiva de atuação junto ao público-alvo dos concursos de Beleza Negra que relatamos:

Nem aos camponeses, nem a ninguém, se persuade ou se submete à força mítica da propaganda, quando se tem uma opção libertadora. Neste caso, aos homens se lhes problematiza sua situação concreta, objetiva, real, para que, captando-a criticamente, atuem também criticamente, sobre ela" (FREIRE, 1983).

Portanto, o relato que faremos, está centrado na observação da importância de construção de representatividades dos oprimidos, neste caso os negros, no sentido de que seja um elemento importante e fundamental na construção de uma identidade positiva sobre si mesmo, um reconhecimento de si de forma crítica, tal qual apontado pela passagem anterior de Paulo Freire.

\section{IFMS: MALUNGOS DE ZUMBI E DANDARA}

A trajetória que culmina no projeto de extensão "Malungos de Zumbi e Dandara" é marcada pelo enfrentamento ao currículo de branqueamento/europeizado, pela construção de 
um currículo do povo negro, em que a Cultura Afro-Brasileira e Africana e sua importância para os brasileiros se torne primordial no processo educacional.

O nome "Malungos de Zumbi e Dandara" é por si mesmo representativo do que se pretende alcançar. O significado de Malungos provém da própria história dos negros escravizados no Brasil. Era o termo que os negros escravizados encontraram para se identificar, com um significado próximo ao que podemos traduzir como "companheiro".

Com o estilhaçamento das relações familiares provocado pelo tráfico, os africanos escravizados buscaram reconstruir em novas bases os laços fundamentais que uniam as pessoas, sendo a ligação entre malungos, como já vimos, a primeira alternativa encontrada, ainda durante a travessia do Atlântico. (SOUZA, 2002, p.181, grifos nossos).

Nesse caso, há no termo o sentido fraternal de reconhecimento e identidade entre negros, que mesmo de origens e tonalidades diferentes, foram e ainda são alvo de preconceito e discriminação no Brasil. Assim, todo preto é um malungo, compartilha das mesmas dores de ser preto em uma sociedade estruturalmente racista, em que a experiência da negritude é opressora.

A outra parte do nome se refere a duas figuras centrais da história do povo negro no Brasil, e mais que isso, da história de resistência à opressão do branqueamento e colonizadora, assim como de luta pelos diretos do negro à liberdade: Zumbi e Dandara dos Palmares. A escolha do casal Palmares se deve a simbologia que ele tem, porque aponta para resistir à opressão da branquitude cultural, e a necessidade de lutar pelo reconhecimento do povo negro no Brasil.

Destarte, "Malungos de Zumbi e Dandara" representa a possibilidade de construir, por meio da educação para as relações étnicos raciais, um currículo em que o negro seja tema central e importante, assim como a cultura afro-brasileira e africana, a fim de que os seus descendentes possam se reconhecer como negros, como sujeitos da história, como primeiro passo de combate a estrutura racista que perdura no país desde sua fundação pelos portugueses. Em contribuição ao assunto, Silva (2010, p. 236) declara:

É necessário colocar a questão dos africanos e afro-brasileiros negros como uma questão importante no contexto nacional, tendo como meta superar a visão negativa construída ao longo de nossa história. Mediante um projeto pedagógico comprometido 


\section{nowite

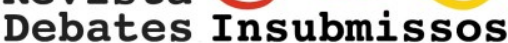

com a eliminação da discriminação racial nas escolas e com a transformação, de forma positiva, do papel do negro na construção da história do Brasil, alterando a lógica eurocêntrica na produção de conhecimento e de cultura, será possível ampliar a permanência da população negra nas escolas.

É oportuno lembrar que a Lei possibilita um novo imaginário de reconhecimento do povo negro no Brasil, não somente por tratar as questões pejorativas, de espoliações e sofrimento, mas de ressignificar a identidade, tornar visível a sociabilidade, as contribuições socioeconômicas e culturais, os saberes e conhecimentos, as suas potencialidades, além da superação dos preconceitos e do analfabetismo. Trata-se de "um conjunto de medidas e ações com o objetivo de corrigir as injustiças, eliminar discriminações e promover a inclusão social e a cidadania para todos no sistema educacional brasileiro" (BRASIL, 2005, p.5).

A SEPPIR resume historicamente a situação do negro na educação, vejamos:

O Brasil, Colônia, Império e República, teve historicamente, no aspecto legal, uma postura ativa e permissiva diante da discriminação e do racismo que atinge a população afrodescendente brasileira até hoje. O Decreto $\mathrm{n}^{\circ} 1.331$, de 17 de fevereiro de 1854 , estabelecia que nas escolas públicas do país não seriam admitidos escravos, e a previsão de instrução para adultos negros dependia da disponibilidade de professores. O Decreto $\mathrm{n}^{\mathrm{o}} 7.031$ - A, de 6 de setembro de 1878, estabelecia que os negros só podiam estudar no noturno e diversas estratégias foram montadas no sentido de impedir o acesso pleno dessa população aos bancos escolares (BRASIL, 2005, p.7).

O projeto de extensão em questão procurou rever, refazer e interferir nas ações pedagógicas educacionais usando, como um dos caminhos, a inserção de novos conteúdos no currículo escolar. Conteúdos esses capazes de problematizar e contestar a visão eurocêntrica, fruto da ideologia da branquitude, na perspectiva de refletir e discutir assuntos das relações étnico-raciais que compõem as culturas africanas e afro-brasileiras. Segundo Gomes (2012, p.19) as demandas devem se voltar "em prol de uma educação democrática, que considere o direito à diversidade étnico-racial como um dos pilares pedagógicos do País".

Para que a lei 10.639/2003 se efetive na prática é necessário rever o Lócus pedagógico, no sentido de reavaliar os conteúdos, o currículo escolar, ações desmobilizadoras de discriminação, relações sociais dos envolvidos no processo, enfatizando a especificidade do segmento negro da população. Enfim, atuar numa perspectiva emancipatória de uma educação para todos e, "por conseguinte, da população negra" (GOMES, 2012, p. 24). 


\section{Revista \\ Debates Insubmissos}

Nesse âmbito da diversidade étnico-racial, é possível dar visibilidade às questões do povo negro não somente por meio das ações pedagógicas, mas também com políticas educacionais, perpassando por uma radicalidade política e pedagógica, resultado da participação de gestores, coordenadores, professores e envolvimento dos discentes no processo histórico.

Considerando o princípio da luta contra o racismo como tarefa primordial da educação no século XXI, uma escola omissa ou cega diante da presença das diferenças socioeconômicas, políticas, culturais e étnico-raciais é uma escola fadada ao fracasso, no sentido de que produz seres violentos, insensíveis, desumanos.

É de fundamental importância expandir a discussão e a reflexão, juntamente com professores, estudantes, pais, autoridades públicas e a comunidade do entorno da escola para, a partir daí, construir experiências educativas como a dos Malungos, que contemplem uma práxis mais intensiva que atenda à realidade escolar, social e cultural, ou seja, nos quais todos se vejam representados.

Uma experiência educativa construída nessa dimensão não admite apenas trabalhar o dia, a semana, o mês. É preciso trabalhar o ano todo a Consciência Negra ou a morte de Zumbi dos Palmares. Exige ir além das fronteiras, de modo a haver comprometimento com a formação educacional, reconhecer os valores da cultura, entender, compreender e superar as práticas racistas impregnadas há séculos neste país, além de "possibilitar uma educação diferenciada, formativa e de abertura às pedagogias ativas" (ANDRÉ, 1999, p. 22), que postula uma dinâmica de reconhecer a desigualdade socioeconômica e étnico-racial e tomar consciência do currículo oficial como fator de exclusão e diferenciação social e étnico-racial.

Tem-se consciência da tarefa árdua, na esperança de realizações e de formações étnicoraciais e culturais que possibilitem a ressignificação da Cultura Afro-brasileira e Africana na construção de uma sociedade mais justa e digna. 
Debates Insubmissos

\subsection{A práxis dos Malungos de Zumbi e Dandara}

O primeiro resultado da execução das semanas da Consciência Negra no campus Três Lagoas foi o interesse de estudantes em realizar projetos relacionados diretamente com a temática. Nos Institutos Federais, os estudantes têm acesso a bolsas de estudos, caminho pelo qual se iniciaram os trabalhos de orientação de projetos relacionados às questões étnico-raciais. Durante esse processo, observou-se que os estudantes careciam de uma maior formação conceitual para que os trabalhos ganhassem mais consistência.

Diante de tal constatação, os coordenadores organizaram, em 2013, um grupo de estudos sobre as relações étnico-raciais, formado por estudantes bolsistas e voluntários, servidores docentes e técnicos-administrativos, além de estudantes de outras instituições, com a finalidade de se reunir uma vez a cada dois meses, com um cronograma de textos pré-definidos, para debater os problemas levantados pelos autores.

Os primeiros efeitos positivos do grupo de estudo foram sentidos aproximadamente um ano e meio depois de seu início, sobretudo em 2015, em que já se percebia que a qualidade do trabalho dos estudantes havia mudado de patamar. No entanto, mesmo que se evidenciasse um salto significativo no âmbito conceitual, ainda não havia - no corpo discente - um salto nas práxis antirracista.

A inércia dos estudantes em transformar o conhecimento obtido sobre o racismo em práxis antirracista ensejou o seguinte problema: como atuar, considerando as lições de Paulo Freire em Extensão e Comunicação, para a transformação da passividade em práxis de resistência?

Após uma reunião do grupo de estudos, uma estudante relatou que a bolsa e os conhecimentos desenvolvidos haviam gerado uma transformação em sua vida, mas que, no entanto, percebia que por mais que se esforçasse para que sua irmã mais nova também transformasse o olhar em relação à questão, não conseguia. Diante de tal fato, ela sugeriu a possibilidade de desenvolver um projeto na escola da irmã.

Diante de tal proposição, orientado pelos ensinamentos de Paulo Freire em Extensão e Comunicação, que propõem não ter os estudantes enquanto tábula rasa, como quem absorve 
e reproduz de forma sistemática o conhecimento, neste caso, sobre a história e a cultura afrobrasileira, no sentido em que se obtenha no processo educativo uma experiência de troca entre o extensionista e o público, que nasceu o projeto de extensão "Malungos de Zumbi e Dandara: Formação básica para a educação das relações étnico-raciais na Escola Municipal Olyntho Mancini em Três Lagoas-MS”.

O projeto teve início no ano de 2016 e passou a desenvolver uma série de atividades na escola municipal, tais como: contação de histórias de origem Africana como forma de valorizar o saber e a história da África; aulas de História da África ministradas pelos professores coordenadores; exibição de curta metragens sobre o racismo; e oficina de confecção de boneca Abayomi.

Além do trabalho em sala de aula, quase sempre acompanhado e auxiliado pelos estudantes bolsistas, houve, também, implementação de ação com os docentes e com a gestão da escola. A proposta era problematizar as questões étnico-raciais percebidas durante desenvolvimento das atividades, assim como, demonstrar aos professores e à gestão escolar que as oficinas eram formativas, e, portanto, seria fundamental que a escola, enquanto coletivo, assumisse a tarefa de educar para as relações étnico-raciais.

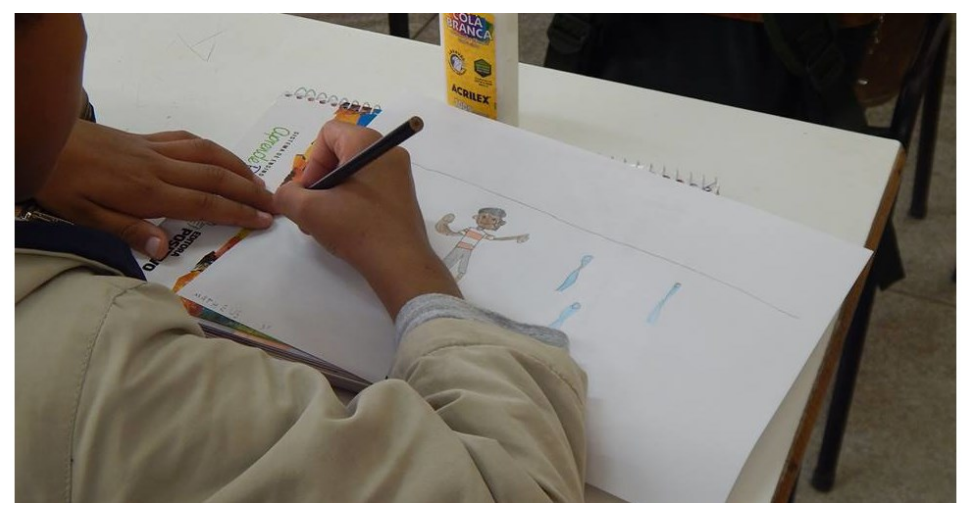

Projeto dá seus primeiros passos na Escola Municipal em 2016.

De fato, o trabalho foi bem acolhido pela comunidade da Escola Municipal Olyntho Mancini, o que colaborou para que as práticas pedagógicas trabalhadas com estudantes e docentes da escola fossem incorporadas ao cotidiano de aprendizagem da comunidade escolar. 


\section{Revista \\ Debates Insubmissos}

Assim, durante o período de desenvolvimento do projeto o tema das relações étnico-raciais e mais especificamente do racismo, passou a ser um tema de constante debate na escola e uma preocupação central no processo de aprendizagem.

Para além da composição do currículo e a inserção do tema no projeto políticopedagógico da escola, a introdução do projeto de extensão no cotidiano da escola se mostrou efetivo no sentido pretendido, isto é, estabelecer um campo de combate ao racismo no processo educacional, como primordial.

Consideramos o "Malungos de Zumbi e Dandara" bem mais abrangente que um projeto de extensão. A experiência vivida nos fez entender que a dimensão do trabalho extrapolou os muros do colégio, tornando-se, ao nosso ver, um movimento, argumento que se torna ainda mais denso com o relato de organização e promoção dos concursos de beleza negra que enunciaremos.

Em síntese, as experiências educativas como a dos Malungos de Zumbi e Dandara revelam que é urgente a educação para relações étnico-raciais, de forma que o negro reconheça a escola como seu lugar.

\section{CONCURSO DE BELEZA NEGRA DO IFMS}

O Concurso de Beleza Negra, objeto desta contribuição ao Dossiê de Extensão da Debates Insubmissos, é ação do projeto de extensão Malungos de Zumbi e Dandara que merece destaque, justamente porque a percepção de transformação do projeto em movimento passa, necessariamente, pela construção dos concursos de beleza negra do IFMS.

Novamente, em uma das reuniões do grupo, no ano de 2016, foi levantada a ideia do concurso por parte de uma estudante que realizava um trabalho de iniciação científica sobre o preconceito racial, analisando como este se manifestava na estética, na questão dos cabelos, algo tão caro para a população negra, sobretudo para as mulheres.

No campus Três Lagoas, naquele momento, a questão da estética negra já era bem resolvida, visto que o próprio desenvolvimento da combinação de ações temáticas no meio 
escolar produziu mudanças nos atores sociais envolvidos nesse processo histórico que se desenrolou concomitantemente à implantação da unidade.

Apareceram os cabelos afros, turbantes, tranças nagôs, batas africanas, camisetas com estampas que lembram a temática negra. Esse fenômeno espontâneo de representatividade produziu também um efeito de autoestima nos estudantes negros envolvidos no projeto.

Munidos de autoestima e entendendo, no exercício de sua existência cotidiana enquanto sujeitos negros, as transformações que haviam sido operadas através do engajamento no projeto, os estudantes sentiram a necessidade de multiplicar o que acontecia no campus.

A passividade cedia lugar à práxis transformadora. O ponto de inflexão, reconhecido por todos eles, tinha uma relação inevitável com a estética africana, e o fim do aprisionamento aos padrões brancos impostos por uma sociedade racista.

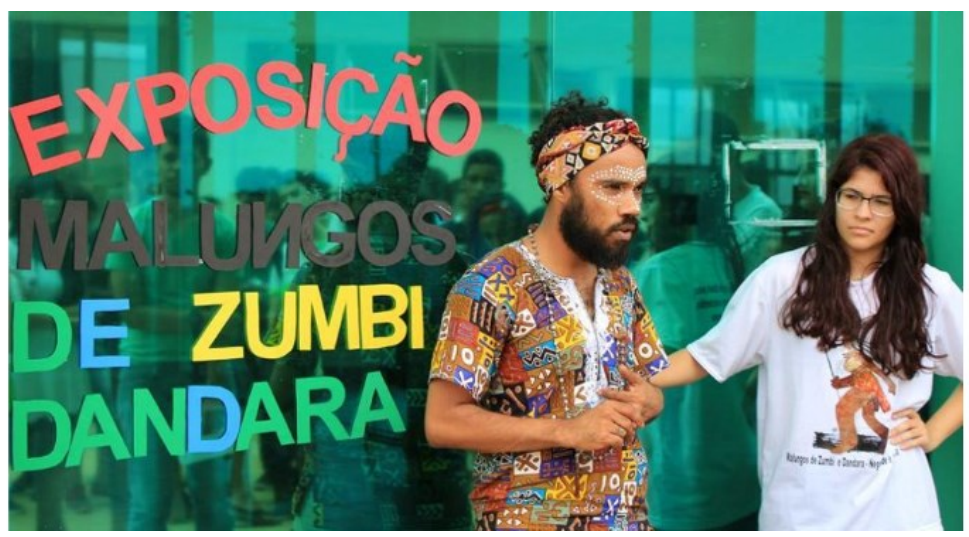

Servidor Guilherme, professor de Sociologia do IFMS, na Semana da Consciência Negra de 2016

O primeiro Concurso de Beleza Negra do IFMS foi organizado naquele ano de 2016, durante a Semana da Consciência Negra, tendo como referência a ideia de beleza enquanto construção social, e que, portanto, pode e deve ser desconstruída, como confirma Braga (2015, p.18): "Os conceitos de beleza construídos em um determinado momento histórico se desfazem em momentos seguintes, transformam-se, carregam novos sentidos, produzem novos padrões, apresentam-se e materializam-se de modo distinto". 
A primeira edição teve 25 inscritos, em sua grande maioria do próprio campus, sendo apenas 5 na categoria masculino. Jovens estudantes de Ensino Médio autodeclarados negros. As fichas de inscrição foram preenchidas à mão e a divulgação foi simples, com alguns materiais impressos, sem utilização das redes sociais. Os vencedores do concurso foram estudantes do IFMS.

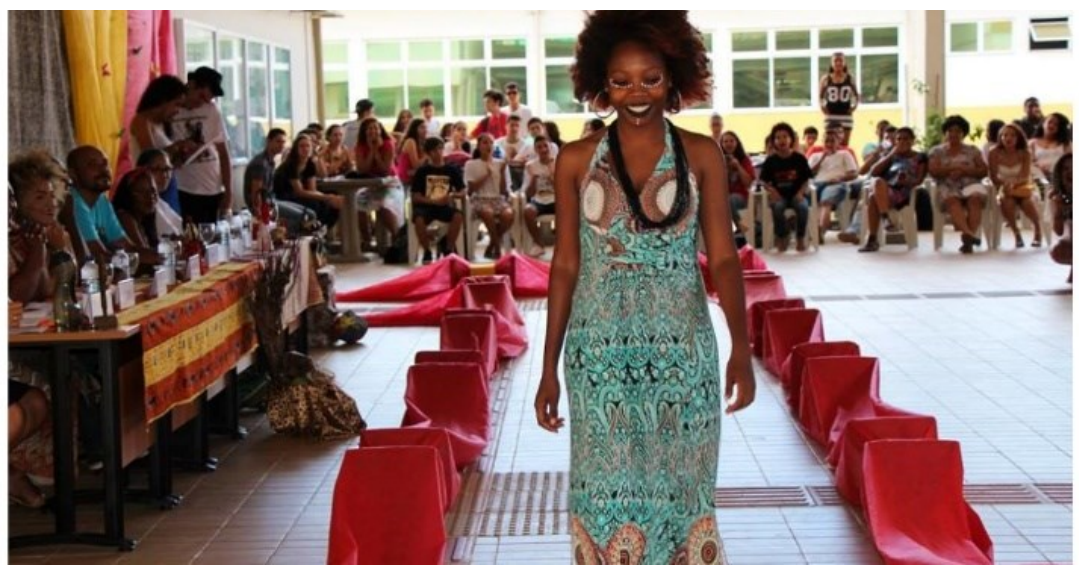

Candidata desfila no primeiro concurso

Os candidatos foram avaliados em três etapas: desfile de trajes, apresentação cultural e perguntas dos jurados. A proposta de participação e avaliação que nascia na primeira edição perduraria nos seguintes, consolidando-se como metodologia para a prática da História e Cultura Afro-Brasileira e Africana.

Assim, não se tratava de reproduzir, com corpos negros, um concurso de beleza tradicional em que pessoas altas, esguias e artificialmente sorridentes desfilam para obter notas altas junto aos jurados. Estava em questão a liberdade no seio da coletividade, de acordo com GOMES (2017, p.109) “A beleza pode ser entendida como uma categoria estética e construção social, como uma maneira de nos relacionarmos com o mundo". 


\section{Revista Debates Insubmissos}

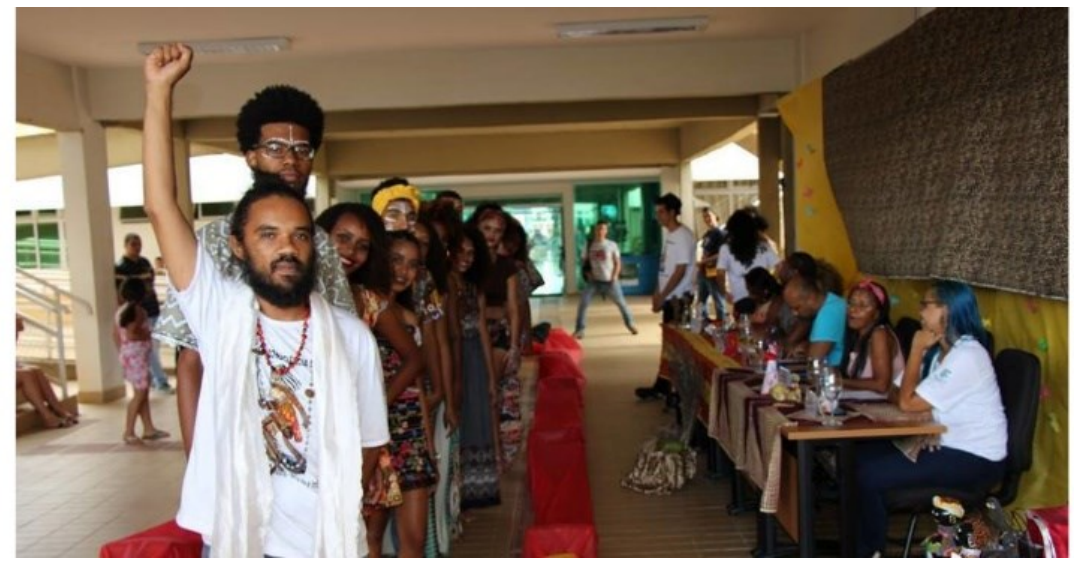

Encerramento do concurso de 2016

A segunda edição, em 2017, foi marcada pela utilização das redes sociais como ferramenta para divulgação do concurso. Surgiu o perfil @malungosdezumbiedandara na rede social Facebook, página que, somada à intensificação na divulgação de escola em escola, de sala em sala, elevou para 40 o número total de inscritos, sendo 25 de escolas públicas, com aumento de 5 para 15 candidatos na categoria masculino.

A estratégia de divulgação das inscrições para a segunda edição contou com ensaio fotográfico com participantes da edição-piloto de 2016 e fez sucesso nas redes sociais. $\mathrm{O}$ cenário escolhido foi a lagoa da cidade, cartão postal do município.

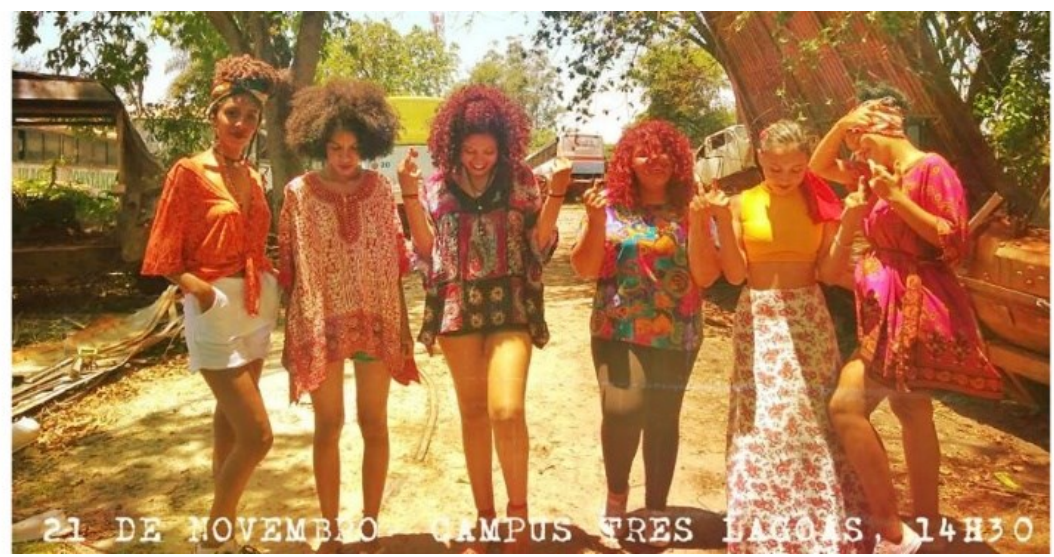

Foto de divulgação da edição de 2017 
A participação massiva das escolas públicas demandou melhorias na estrutura física e a participação de mais discentes e servidores na execução do concurso. Todavia, os fatos de destaque são mesmo qualitativos. O vencedor da edição de 2017 foi um jovem matriculado em escola pública, imigrante haitiano, chamado Sunley, que na etapa da apresentação cultural apresentara um poema declamado em créole.

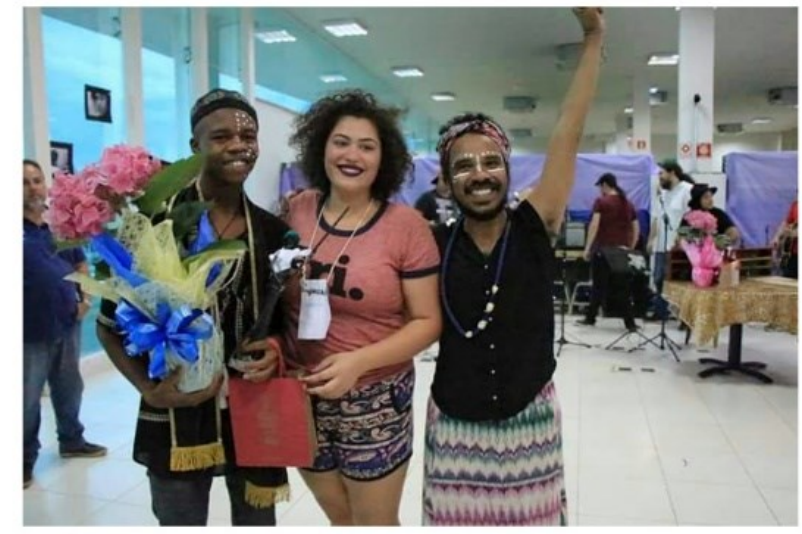

A esquerda, o Mister Beleza Negra 2017

O Concurso de Beleza Negra de 2017 ocorreu no dia 21 de novembro daquele ano. Um dia antes, o professor de Sociologia e coordenador do projeto de extensão, Guilherme Costa Garcia Tommaselli, a convite, esteve no campus Votuporanga do IFSP para ministrar a palestra "Afinal, o que é Consciência Negra?", dentro da programação da Semana da Consciência Negra. Ao final da palestra, o docente lançou o desafio para que a unidade do IFSP promovesse concurso similar, o que ocorreria em 2018 por meio de programa institucional, selando a colaboração interinstitucional IFMS/IFSP através do projeto de extensão Malungos de Zumbi e Dandara.

Entretanto, cabe relatar a edição 2018 do concurso do campus Três Lagoas, marcada pelo aprimoramento na execução do evento, consolidando patamar organizativo que estabelece a ação como referência para a Rede Federal de EPC\&T.

Na edição em questão, após reuniões de avaliação das duas experiências anteriores, a equipe do projeto decidiu por envidar esforços no acolhimento dos candidatos, estabelecendo a figura do "anjo", papel a ser desempenhado por participante do ano anterior que ambienta, tranquiliza e colabora com um ou mais candidatos da edição em execução. 


\section{Revista \\ Debates Insubmissos}

A organização pleiteia, também, junto ao IFMS, a disponibilização de plataforma online para divulgação e inscrição dos candidatos, o que ocorre com algum atraso. Nesse ínterim, os campi Três Lagoas e Votuporanga já dialogam intensamente para a estruturação da proposta de projeto a ser submetido junto ao IFSP.

Enquanto a articulação interinstitucional ocorre e a plataforma online é desenvolvida em Mato Grosso do Sul, os Malungos de Zumbi e Dandara passam a utilizar o Instagram, rede social emergente, para impulsionar a divulgação da terceira edição com fotos de ensaio com participantes de 2017.

Mais, enquanto aguardam a plataforma online e a assimilação institucional do evento por parte da Pró-Reitoria de Extensão, os Malungos, atentos à conjuntura nacional do ano eleitoral e às manifestações factuais de racismo e de negação às mazelas da escravidão, sobretudo na mídia e nas redes sociais, lançam campanha contra o racismo. Basicamente com participações voluntárias por meio de envio de foto em preto e branco, as redes sociais do projeto publicam imagens que denunciam o preconceito e o racismo vivido por pessoas que se dispuseram a denunciar as ofensas que já ouviram. 


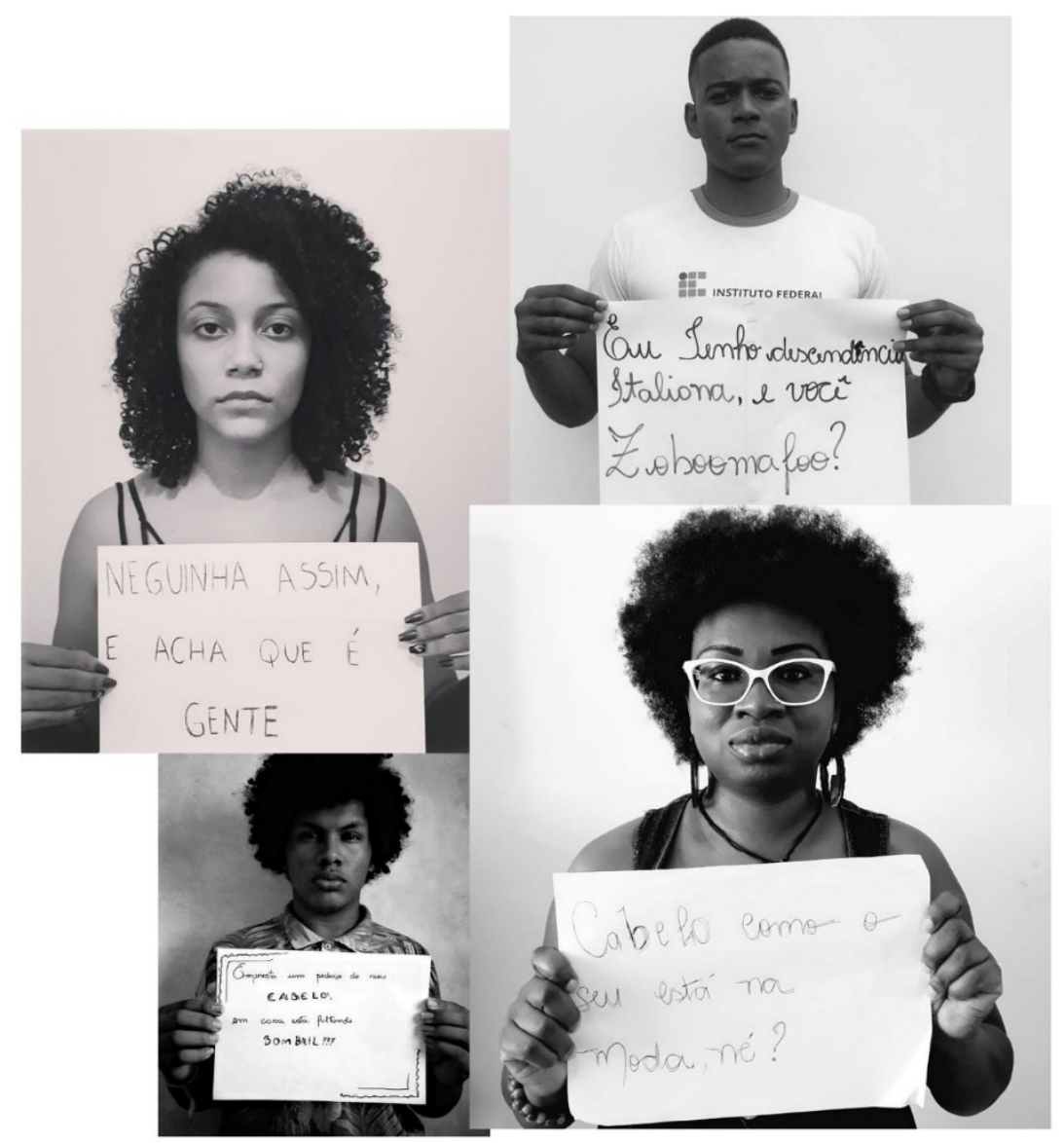

Ao todo, foram mais 40 publicações denunciando o racismo entre setembro e novembro de 2018.

O IFMS disponibiliza o sistema de inscrições online e os Malungos reforçam a divulgação, obtendo 27 inscrições. Além do sistema de inscrições, um professor do campus Três Lagoas, identificado com a causa defendida pelo projeto, desenvolve um sistema eletrônico para pontuação e apuração do concurso de beleza. Novamente em três etapas, com desfile de trajes, apresentação cultural calcada na temática e perguntas dos jurados sobre história e cultura, os Malungos movimentam a escola. 


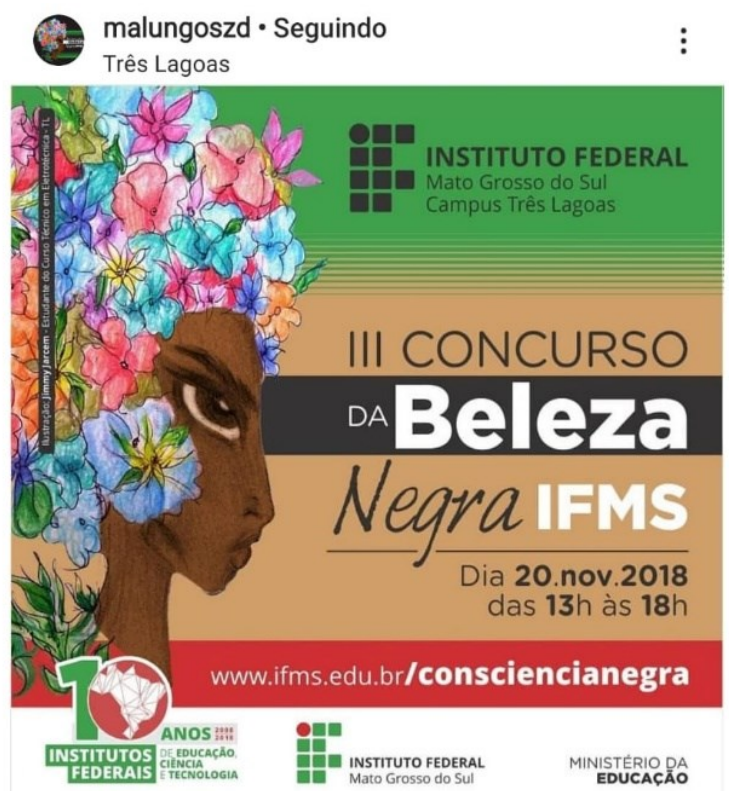

Print de postagem na rede social Instagram, contendo a divulgação oficial da edição 2018.

A edição de 2018 marca o ápice da qualidade das apresentações culturais e das respostas dos candidatos e candidatas às perguntas dos jurados, demonstrando domínio, identificação com o tema e disposição para a luta antirracista.

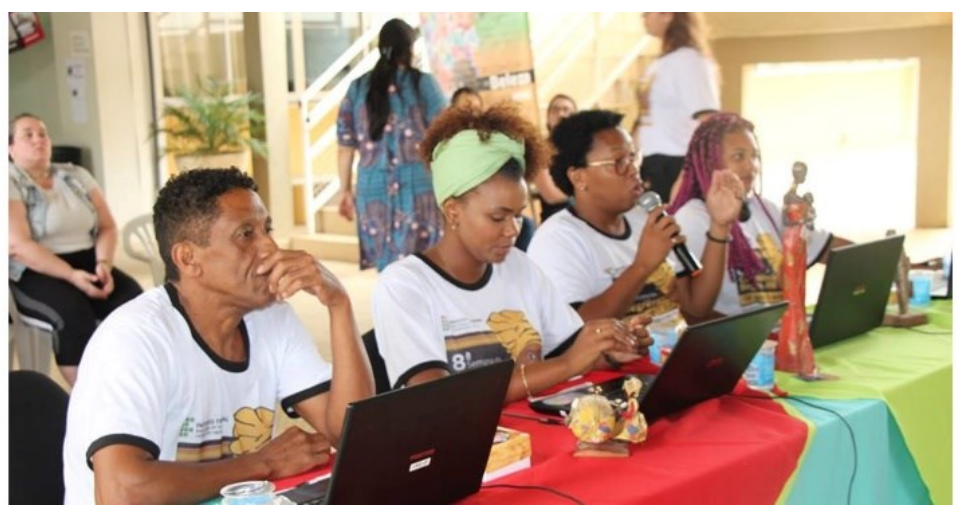

Jurados com lugar de fala e assistidos por sistema para lançamento e apuração de notas 
Revista

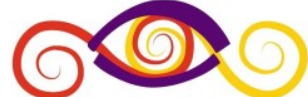

Debates Insubmissos

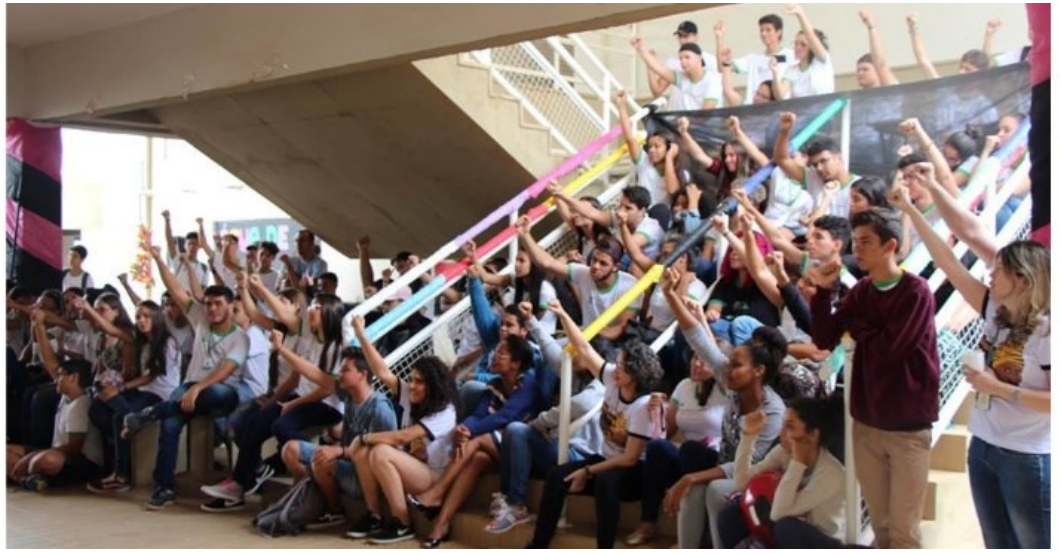

Público do concurso
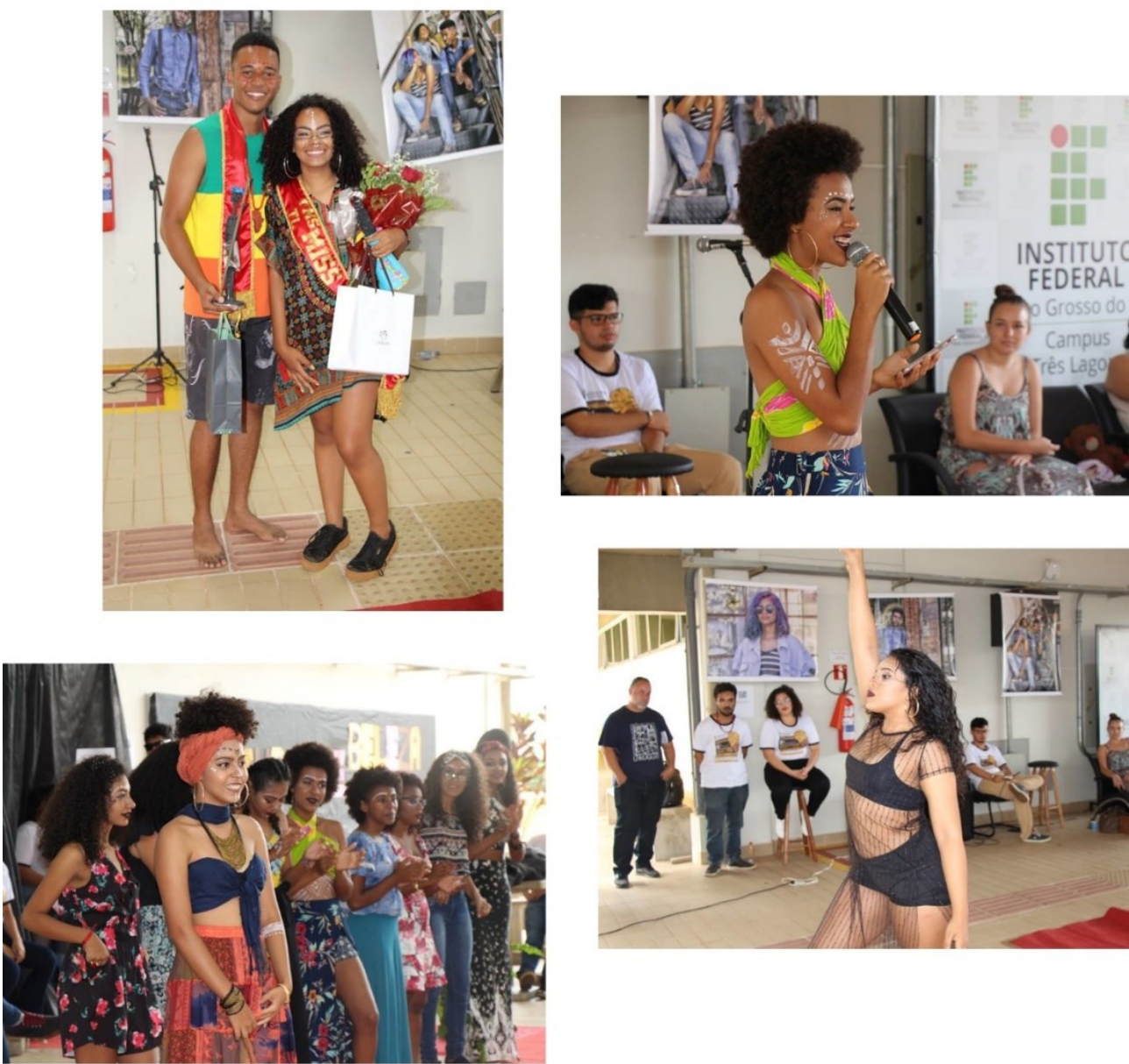

Terceira edição do concurso consolida a metodologia e supera padrões 


\title{
Revista \\ Debates Insubmissos
}

Nessa edição, houve a oferta de oficinas formativas, incluindo dança, pinturas, confecção adereços e outros aspectos relacionados à temática, fator decisivo para a elevação da qualidade da participação dos candidatos.

A inserção das oficinas foi fruto do diálogo com o campus Votuporanga, que havia proposto ao IFSP, quando da submissão do projeto, em setembro de 2018, a oferta de disciplinas que subsidiassem a apresentação cultural e a etapa de perguntas dos jurados.

Como se vê, os Malungos passam a se retroalimentar de processo educativo desenvolvido em outra instituição por inspiração e influência de seu trabalho. Tal fenômeno os aproximam da percepção de movimento educacional.

\section{IFSP: "NEABI EM AÇÃO"}

\begin{abstract}
Trata-se de proposta, sob o formato de projeto, que versa sobre a execução de Concurso de Beleza Negra no campus Votuporanga do IFSP, focalizado no público autodeclarado negro que, devidamente matriculado no Ensino Médio no referido campus, em escola particular ou em escola pública estadual do município em questão, inscreva-se para participar de certame artístico e cultural relativo à valorização da população afrodescendente no imaginário popular, de modo a promover elevação de autoestima, a educação para as relações étnico-raciais, a luta contra o racismo e o interesse pela História da África, bem como a quebra de paradigmas estéticos relacionados a indústria cosmética e da moda, além dos padrões vigentes na propaganda comercial, por meio de metodologia de participação e avaliação caracterizada pela superação do modelo tradicional de concurso de beleza. (MICENO, 2018)
\end{abstract}

Importa citar trecho do resumo da proposta submetida junto ao programa "Neabi em Ação" do IFSP em setembro de 2018 para evidenciar o alcance da problematização que se pretendia junto ao público-alvo, de modo que a experiência acumulada no campus Três Lagoas pudesse florescer com densidade na Semana da Consciência Negra de 2018.

O Núcleo de Estudos Afro-Brasileiros e Indígenas (Neabi) do IFSP lançou o edital do "Programa Neabi em Ação" em agosto de 2018, contemplando 19 propostas entre os mais de 35 campi da instituição. Votuporanga aprovou o projeto "Concurso de Beleza Negra", obtendo 1 (uma) bolsa de extensão no valor mensal de $\mathrm{R} \$ 400,00$ com pagamento em setembro, outubro e novembro. 


\section{Revista \\ Debates Insubmissos}

Tratava-se de um programa que oxigenaria projetos dentro de um cronograma apertado. Se considerarmos que os eventos no IFSP, por força de regulamento institucional, podem ser viabilizados por Chamada Pública, a equipe do projeto, formada por uma bibliotecária e um assistente em administração, viu-se no desafio de redigir e articular a publicação e divulgação de 3 (três) editais: de seleção do bolsista, de Chamada Pública para apoio ao evento e o do regulamento do concurso em si. Este último, detentor de cronograma que parte de inscrições com a devida antecedência e chega até a execução do evento em si.

A estudante Mayara Alexandra da Silva, do curso de Engenharia Civil e que aparece na página 14 deste relato com a placa "Neguinha assim e acha que é gente" foi escolhida bolsista do projeto. Autodeclarada negra e detentora de Índice de Rendimento Acadêmico (IRA) altíssimo, logo se engajou nas atividades e foi decisiva na divulgação do edital do concurso.

Rigorosamente, por mais de duas semanas, a equipe do projeto visitou todas as salas de aula de Ensino Médio da rede pública de Votuporanga, além de 1 escola particular. Por motivo do feriado de "saco cheio", a maioria das escolas particulares estava sem aulas durante a divulgação das inscrições para o concurso.

A metodologia do concurso desenvolvido em Votuporanga utilizou a implementada no IFMS, prevendo Desfile de Trajes e Adereços, Apresentação Cultural e Perguntas dos Jurados. O esforço de divulgação obteve resultado expressivo no número de inscritos: 29 inscritos, em sua maioria das escolas pública da cidade, sendo apenas 6 na categoria masculino.

Quando da submissão da proposta ao programa de extensão, a equipe do projeto teve de se comprometer a oferecer 2 (duas) ou mais oficinas, como forma de cumprimento do regulamento institucional das Ações de Extensão, que prevê que todo projeto execute ao menos 3 ações. Em que pese o concurso de beleza ser robusto e complexo o suficiente, estruturado numa sequência de datas e atividades, fez-se necessário recorrer aos artesãos, artistas e afroempreendedores, por meio de Chamada Pública, para a oferta de oficinas informativas e formativas. 
Desse modo, erigiu-se estrutura que ofertou aos candidatos e a comunidade em geral, mais de 300 vagas em oficinas temática, como se pode ver na notícia publica no sítio eletrônico do campus Votuporanga:

A equipe do projeto de extensão "Concurso de Beleza Negra" divulga a programação das Oficinas preparatórias,
destinadas aos candidatos inscritos e abertas a toda a comunidade:

\begin{tabular}{|c|c|c|c|c|c|c|}
\hline Oficina & Responsável & Data & Horário & Local & Vagas \\
\hline História e Cultura Afro-Brasileira & Leandro Clemente & $07 / 11$ & $15 \mathrm{~h} 30$ às $17 \mathrm{~h}$ & Anfiteatro & 40 \\
\hline Cuidados com cabelos cacheados e crespos & Danitiele Gonçalves & $07 / 11$ & $17 \mathrm{~h} 15$ às $18 \mathrm{~h} 45$ & Bloco E Sala 7 & 40 \\
\hline Maquiagem & Bianca Vitalino & $08 / 11$ & $17 \mathrm{~h} 15$ às $18 \mathrm{~h} 45$ & Auditório & 20 \\
\hline Pinturas Tribais & Sllvia Silva & $10 / 11$ & $8 \mathrm{~h}$ às $9 \mathrm{~h}$ & Anfiteatro & 30 \\
\hline Dança Afro-Brasileira & Sllvia Silva & $10 / 11$ & $9 \mathrm{~h}$ às $10 \mathrm{~h}$ & Anfiteatro & 30 \\
\hline Confecçăo de bonecas Abayomis & Fátima Barbosa & $10 / 11$ & $10 \mathrm{~h} 30$ às $11 \mathrm{~h}$ & Anfiteatro & 40 \\
\hline Máscaras Africanas & Estudantes do cămpus & $10 / 11$ & $9 \mathrm{~h}$ às $10 \mathrm{~h} 30$ & Anfiteatro & 60 \\
\hline Confecçăo de Biojoias & Fátima Barbosa & $12 / 11$ & $17 \mathrm{~h} 15$ às $18 \mathrm{~h} 45$ & Bloco E Sala 7 & 20 \\
\hline Turbantes & Fátima Barbosa & $12 / 11$ & $17 \mathrm{~h} 15$ às $18 \mathrm{~h} 45$ & Bloco E Sala 7 & 20 \\
\hline Trança & Danitiele Gonçalves & $13 / 11$ & $17 \mathrm{~h} 15$ às $18 \mathrm{~h} 45$ & Bloco E Sala 7 & 40 \\
\hline Turbantes & Danitiele Gonçalves & $13 / 11$ & $17 \mathrm{~h} 15$ às $18 \mathrm{~h} 45$ & Bloco E Sala 7 & 40 \\
\hline
\end{tabular}

Para participar, basta comparecer no câmpus Votuporanga e procurar a equipe do projeto.

Os candidatos inscritos no concurso já participaram de oficinas de Capoeira e Artes Cênicas, ministradas pelo estudante Victor Hugo, do curso de Engenharia Civil, e pelo professor de Portugês e Redaçåo Eduardo Catanozi, respectivamente.

Print de notícia institucional contendo quadro de oferta de oficinas

Porém, ao longo do processo de participação dos candidatos nas oficinas, houve acentuada evasão. "Não tenho roupa". "Não tenho ideia de apresentação cultural". "Pensei que fosse apenas desfile". "Moro muito longe e fica difícil ir nas oficinas". Embora não tenha sido possível coletar o motivo exato da desistência de candidatos, um fator se destacou quando das tentativas telefônicas de contato: a mobilidade urbana, combinada com a necessidade de trabalhar. 
O desfile de trajes e adereços ocorreu no dia 19 de novembro, após a abertura oficial da Semana da Consciência Negra, cuja programação fora toda estruturada pelo projeto, em virtude da inação da representação local do Neabi.

No dia 21 de novembro, uma quarta-feira, ocorreram as apresentações culturais e a arguição dos jurados. 2 jovens na categoria masculino e 7 no feminino concluíram as três etapas do concurso. Qualitativamente, os jovens remanescentes demonstraram plena sinergia com a proposta do concurso.

A mesa de jurados foi composta por uma radialista, pelo presidente do Conselho Negro de Fernandópolis, cidade vizinha, e pelo professor de Sociologia do campus Três Lagoas, que um ano antes havia provocado o campus Votuporanga a organizar o concurso.

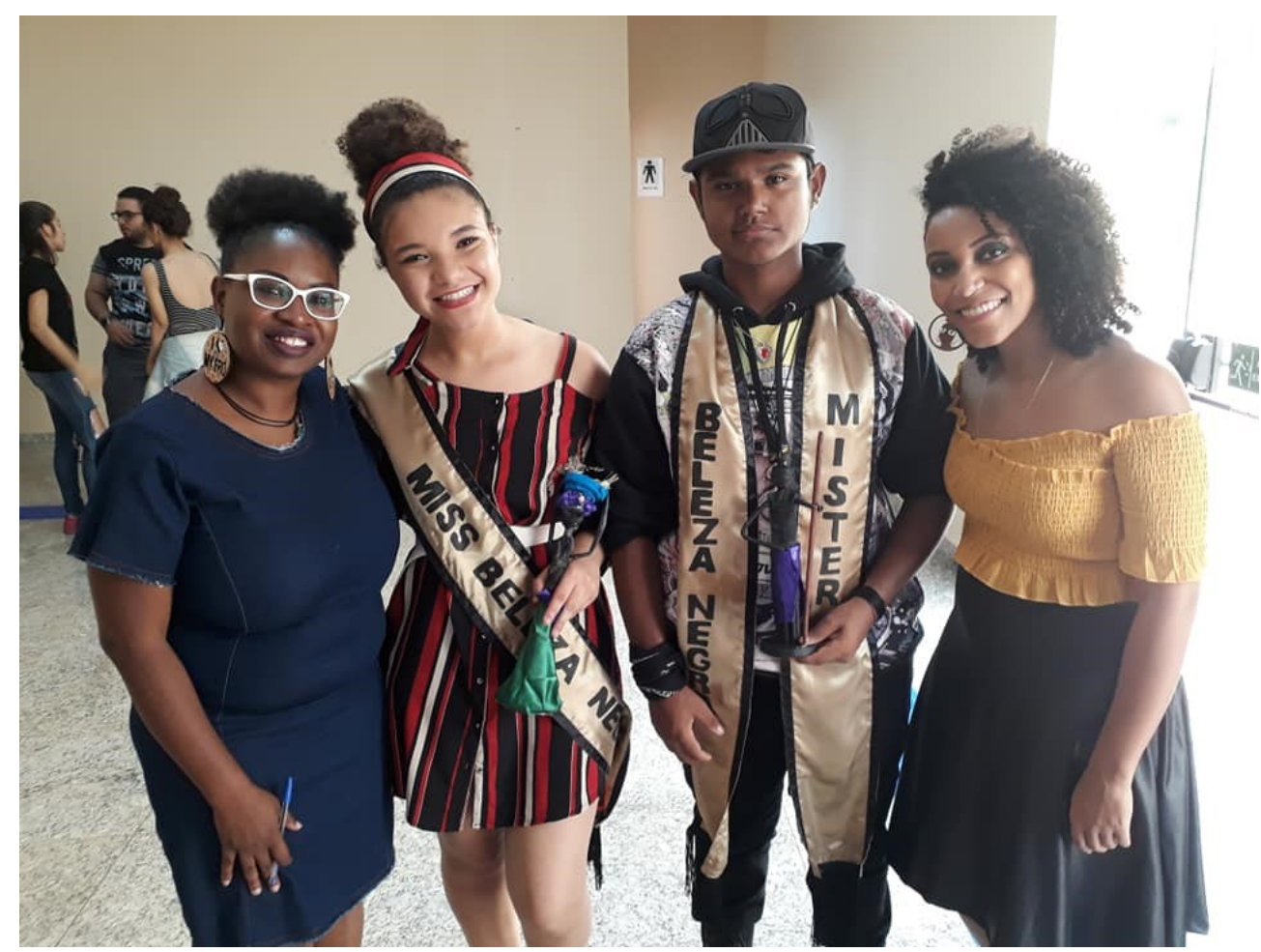

Servidora Tatiane, bibliotecária e coordenadora do projeto, ao lado do Miss e Mister Beleza Negra 2018 e de Mayara, estudante e bolsista do projeto 


\section{RESULTADOS OBTIDOS}

O reconhecimento, por parte do IFMS, da qualidade do trabalho desempenhado em Três Lagoas, através do incentivo institucional, para que os professores de História e Sociologia da unidade visitem os demais campi para troca de experiência que impulsione a organização estruturada e tematicamente densa das Semanas da Consciência, dentro da perspectiva de construção diária inerente à educação para as relações étnico-raciais.

Se em Votuporanga o elevado número de inscritos foi comemorado pela equipe e a elevada taxa de desistência foi motivo de lamento, o depoimento da bolsista na rede social Facebook, após participar do Congresso de Extensão (Conemac) do IFSP no campus Barretos, na semana seguinte ao concurso, materializa o ganho na formação de liderança antirracista no meio acadêmico, sobretudo se levarmos em conta que o curso de Engenharia Civil nas instituições públicas (e aqui falamos de ethos também) é historicamente dominado por homens e, em sua maioria absoluta, por pessoas brancas. Postou ${ }^{4}$ a bolsista Mayara Alexandra da Silva em 28 de novembro de 2018:

"Eu sou preta. Não um pouco mais morena, ou mulata.. preta ! A única denominação que deveriam me dar, mas parece que as pessoas tem medo de me classificar assim. Nasci e convivi com pessoas de maioria brancas. Minhas professoras, diretoras eram brancas, minhas amigas eram brancas.. pq graças a Deus eu nasci numa família que tinham condições de pagar uma escola particular pra mim. Mas, infelizmente, pelo visto isso não acontece com muitas famílias negras, já que na maioria das vezes, eu era a única negra na escola. Mas, na vdd, so percebi que era a unica, "a diferente " quando começaram a fazer piadas sobre a minha cor. A principio eu achava que não ligava, pq não me fazia chorar.. mas com o tempo, as piadas me faziam tentar "me encaixar ", tentar entrar no padrão deles... como alisar o cabelo, comecei a parar de usar certas cores de roupa pq sabia que surgiria algum tipo de piada relacionado a minha cor e a minha cor de roupa.. Mas eu estava sozinha! Nao sabia nem como conversar com alguém sobre isso, pq achava que não iam me entender! Com o passar do tempo, eu fui entendendo que seria sempre assim e que piadas não poderiam me modificar. Comecei a entender que nao valia o meu esforço pro meu cabelo ficar liso, ja que meu cabelo enrolado também era lindo. Comecei a me aceitar como preta de vdd, amar meu cabelo, minha cor, meu nariz; minha raça. E que nenhuma piada seria suficiente pra mudar meu estilo de vida e meus pensamentos. Depois de ter passado por tudo isso e ter me aceitado, me apareceu esse projeto: concurso de beleza negra. Um projeto lindo que objetiva ajudar adolescnetes negra/os a se aceitarem e se amarem! Eu não tive ajuda com isso, então eu queria poder ajudar outras pessoas. E

\footnotetext{
${ }^{4}$ Foi mantida a grafia da postagem.
} 


\section{Revista \\ Debates Insubmissos}

foi isso que me deu força e garra pra ir com ele até o fim, pra poder ajudar a maior quantidade de pessoas que fosse possível! Agradeço imensamente a Tati e ao Augusto por me darem a oportunidade de fazer parte desse projeto maravilhoso. Hoje o apresentei no congresso e pelos comentários e elogios percebi o quanto ele é importante! E por fim, gostaria de dizer que eu não escolhi ser negra, mas se pudesse, escolheria ser exatamente como sou ! \#conemac"

\section{CONCLUSÕES}

A experiência dos Malungos em desenvolver o concurso de beleza negra parte da proposta de emancipar os corpos negros, como alternativa para enfrentar a realidade racista que impõe aos corpos negros o lugar de marginalização, de violência, de não desejados, de não belos. Nesse sentido, a proposta de colocar em evidência a beleza negra trouxe aos Malungos o sucesso, não alcançado até então, no que diz respeito à transformação dos sujeitos negros em combatentes do racismo. De acordo com Gomes (2017, p.111) “A construção política da beleza negra, no final da década de 1970 e início dos anos de 1980, emancipa o corpo negro ao valorizar um padrão estético colocado sob suspeita no contexto do racismo".

A realização do concurso de beleza negra tem se mostrado uma ação eficiente no que diz respeito à construção de uma nova postura dos negros e negras quanto a sua identidade, história, cultura, e em um âmbito mais específico, quanto a emancipação do seu corpo.

Desse modo, a beleza negra é compreendida como caminho de reconhecimento da própria experiência e existência negra, tal qual aponta Gomes (2017, p.109):

De um ponto de vista antropológico, a experiência estética do corpo, ou seja, aquela que temos frente a um objeto ou um corpo ao senti-lo como belo, faz parte da experiência humana, e as formas de codificar o belo e o feio são particularidades culturais que sofrem alterações às vezes drásticas, outras não, no decorrer do processo histórico e político.

Portanto, tem-se consciência da tarefa árdua, mas não impossível, considerando estar imbuídos na esperança de realizações e de formações étnico-raciais e culturais que possibilitam a ressignificação da Cultura Afro-brasileira e Africana na relevância da construção de uma sociedade mais justa e digna e, especificamente, para a população negra. Nessa perspectiva, experiências educativas como Malungos de Zumbi e Dandara revelam que é urgente a educação 
para relações étnico-raciais, em especial no contexto político que vivemos, como afirma Gomes (2017, p.113):

Contudo, com o impedimento da presidenta democraticamente eleita, Dilma Rousseff, em agosto de 2016, o pais entrou em um clima de retrocessos políticos e econômicos e de reorganização das políticas à luz do mercado e dos princípios neoliberais. $\mathrm{O}$ impeachment, que pode ser interpretado como um novo tipo de golpe de estado que assolou o Brasil e se desenvolveu em outros países da América Latina, a partir da segunda década de 2000, é marcado por uma reorientação neoliberal das políticas, na qual as questões de gênero, diversidade sexual, raça, juventude e direitos humanos, as leis trabalhistas, a previdência social, a garantia de empregos têm sido drasticamente negadas e vários direitos conquistados pelos brasileiros e brasileiras, desde a década de 30 do século XX, passam a ser ameaçados. A perspectiva é de mais ação do Movimento Negro para manter as suas conquistas nesse árduo de luta por direitos e mais intensidade nas suas ações de combate ao racismo.

Assim sendo, projetos de extensão, tal qual Malungos de Zumbi e Dandara, são fundamentais para manutenção dos espaços e direitos conquistados pelo Movimento Negro, e que contribuem para a construção de um campo de conflito, que é necessário, para que se enfrente este momento histórico de ascensão de forças conservadoras e autoritárias, que já demonstraram que estão incomodadas com esse processo de ascensão social, cultural e política do povo negro. Assim, os concursos de Beleza Negra, no IFMS e no IFSP, são demonstrações de como estabelecer um campo de conflito, na tentativa de manter viva as conquistas do movimento negro, e da própria liberação do corpo negro do padrão branco.

\section{REFERÊNCIAS}

ANDRÉ, Marli Eliza Dalmazo Afonso de (Org.). Pedagogia das diferenças na sala de aula. Campinas, SP: Papirus, 1999.

FREIRE, Paulo. Extensão ou comunicação. São Paulo, Editora X, 1900.

BRAGA, R. A Política do precariado: do populismo à hegemonia lulista. Ed. Boitempo, São Paulo, 2012.

BRASIL. Secretaria de Educação Fundamental. Parâmetros curriculares nacionais: pluralidade cultural, orientação sexual. Brasília: MEC/SEF, 1997.

BRASIL. Diretrizes curriculares nacionais para a educação das relações étnico-raciais e para o ensino de história e cultura afro-brasileira e africana. Ministério da Educação e a 
Secretaria Especial de Políticas de Promoção da Igualdade Racial. Brasília, DF: Ministério da Educação, 2004.

BRASIL. Diretrizes curriculares nacionais para a educação das relações étnico-raciais e para o ensino de história e cultura afro-brasileira e africana. Ministério da Educação e a Secretaria Especial de Políticas de Promoção da Igualdade Racial. Brasília. DF: Ministério da Educação, 2005.

BRASIL. Ministério da Educação. Secretaria da Educação Continuada, Alfabetização e Diversidade. Orientações e Ações para Educação das Relações Étnico-Raciais. Brasília: SECAD, 2006.

BRANDÃO, Carlos Rodrigues. O que é educação. São Paulo: Brasiliense, 1985.

FREYRE, G. Casa grande \& senzala: formação da família brasileira sob o regime de economia patriarcal. Rio de Janeiro: Maia \& Schmidt, 1933.

GOMES, Nilma Lino. Diversidade cultural, currículo e questão racial: desafios para a prática pedagógica. In. ABRAMOWIZ, Lucia Maria de Assunção Barbosa; SILVÉRIO, Valter Roberto. Educação como prática da diferença. Campinas, SP: Armazém do Ipê. 2006. GOMES, Nilma Lino. O Movimento negro educador: saberes construídos nas lutas por emancipação. Petrópolis, RJ: Vozes, 2017.

GOMES, Nilma Lino. Indagações sobre currículo: diversidade e currículo. Brasília: Ministério da Educação, Secretária de Educação Básica, 2007.

GOMES, Nilma Lino. Práticas pedagógicas de trabalho com relações étnico-raciais na escola na perspectiva da Lei $\mathbf{n}^{\mathbf{0}} \mathbf{1 0 . 6 3 9 / 0 3}$, Brasília: MEC; UNESCO, 2012.

GUSMÃO, Neusa Maria Mendes de. Diversidade, cultura e educação: olhares cruzados. São Paulo: Biruta, 2003.

LARAIA, Roque de Barros. Cultura: um conceito antropológico. 14 ed. Rio de Janeiro: Jorge Zahar, 2001.

LOPES, Ana Lúcia. Currículo, escola e relações étnico-raciais. In. Educação - africanidades -Brasil. Brasília, 2006. p. 13 a 31. 
MICENO, Augusto Mullar. Projeto de extensão Neabi-IFSP em ação: concurso Beleza Negra. Votuporanga: Instituto Federal Educação, Ciência e Tecnologia de São Paulo, 2018. PEREIRA, Edimilson de Almeida. Malungos na escola: questões sobre culturas afrodescendentes e educação. São Paulo: Paulinas, 2007.

OLIVEIRA, Iolanda de. Raça, Currículo e Práxis Pedagógica. In: OLIVEIRA, Iolanda de; SISS, Ahyas. População negra e educação escolar. Cadernos Penesb. Niterói: UFF. $n^{0}$. 7. P. $1-320,2006$. p. 43 à 70.

SILVA, Giovani José da; SOUZA, José Luiz de. Educar para a Diversidade Étnico-Racial e Cultural: Desafios da Educação Inclusiva no Brasil. Inter-Ação: Rev. Fac. Educ., Goiânia, v.33, n. 1, p. 169-192, jan./jun. 2008.

SILVA, Eronildo José da. Lei n ${ }^{\circ}$ 10639/03 - Ensino de História e Cultura Afro-brasileira e Africana: como sua implementação é viável/ possível na escola?. In: CARVALHO, Elma Júlia Gonçalves de; FAUSTINO, Rosangela Célia. Educação e diversidade cultural. Maringá: Eduem, 2010.

SOUZA, Marina de Mello e. Reis negros no Brasil escravista: história da festa de coroação de Rei Congo. Editora UFMG, Belo Horizonte- MG, 2002.

Submetido em: 30/06/2019

Aprovado em: 13/10/2019 